\title{
Conservação do patrimônio paleontológico do Geopark Araripe (Brasil): enquadramento, estratégias e condicionantes
}

\author{
Conservation of geological heritage of Geopark Araripe (Brazil): framework, strategies and \\ constraints \\ MARIANA VILAS BOAS*, JOSÉ BERNARDO R. BRILHA*, FLAVIA FERNANDA DE LIMA** \\ *Universidade do Minho, Portugal - mariana1763@gmail.com - jbrilha@dct.uminho.pt \\ **Geopark Araripe - flaferlima@yahoo.com.br
}

\begin{abstract}
Resumo
O reconhecimento da importância geológica do Geopark Araripe é, em grande parte, fruto da sua riqueza paleontológica, destacando-se a bacia sedimentar do Araripe que contém, à escala mundial, uma das mais importantes associações fossilíferas do Cretáceo Inferior. Infelizmente, apesar do impedimento legal, continua a se verificar o comércio ilegal de fósseis da bacia do Araripe e a saída de muitos deles do país. Os mais raros e com melhor grau de preservação, que adquirem deste modo um excepcional valor científico, são os alvos privilegiados deste comércio. São várias as causas para esta situação, que está documentada há décadas, mas que tarda em se encontrar uma solução. Com este trabalho pretende-se promover ações que integram uma estratégia de educação formal e informal, no sentido de consolidar a prática da geoconservação do patrimônio paleontológico do Geopark Araripe. Embora se reconheça que os resultados e efeitos concretos destas propostas não sejam imediatos, são iniciativas que podem ser utilizadas numa estratégia de geoconservação. Estas ações são aplicáveis no Geopark Araripe, assim como em outras áreas fossilíferas do Brasil e do mundo.
\end{abstract}

Palavras-chave: patrimônio paleontológico, fósseis, geoconservação, Geopark Araripe.

\begin{abstract}
The geological recognition of the importance of the Araripe Geopark is mainly due to palaeontological features, with emphasis on the Araripe sedimentary basin that contains one of the most important fossil associations of the world for Lower Cretaceous rocks. Unfortunately, despite the existent legal framework, the illegal trade of fossils of the Araripe basin is still active with the consequent smuggling of many fossils out of the country. The main targets for this trade are the rarest fossils with perfect preservation conditions, which acquire an exceptional scientific value. There are several causes for this situation that is documented for decades but with no efficient solution implemented so far. This work intends to promote and disseminate several activities that may integrate a formal and informal education strategy in order to consolidate the geoconservation of the palaeontological heritage in the Araripe Geopark. As any other educational plan, the expected results will not be immediate but, even so, these proposals can be applied in the geoconservation strategy of the Araripe Geopark or in any other fossil areas of Brazil and of the world.
\end{abstract}

Key words: palaeontological heritage, fossils, geoconservation, Araripe Geopark.

\section{INTRODUÇÃO}

A geoconservação tem como objetivo a conservação e gestão do patrimônio geológico, materializado pelo "conjunto de todos os geossítios inventariados e caracterizados numa dada área ou região" (Brilha 2005). De acordo com este autor, uma estratégia de geoconservação pretende manter a integridade física dos geossítios, assegurando um adequado uso científico, educativo ou turístico. As iniciativas de gestão de geossítios devem ser adaptadas ao tipo de elemento geológico que interessa salvaguardar. A conservação de um geossítio geomorfológico, por exemplo, pode não ser conseguida usando as mesmas estratégias que são aplicadas a um geossítio mineralógico ou paleontológico.

O patrimônio paleontológico possui diversas especificidades face a outros tipos de patrimônio geológico. Concretamente, deve ter-se em consideração que a conservação de geossítios paleontológicos não se restringe à conservação exclusiva dos fósseis, uma vez que o seu contexto geológico também deve ser valorizado (Henriques 2007). No entanto, em algumas situações, este objetivo pode não ser o mais apropriado, e pode até mesmo ser impossível de alcançar, havendo a necessidade de enveredar por uma gestão equilibrada do local, onde muitas vezes a preservação de um sítio ou de um espécime in situ pode não ser o melhor interesse para a ciência (Besterman 1988). Em muitas situações, a melhor maneira de preservar fósseis consiste no seu resgate e transporte para instituições que possam 
assegurar a sua proteção. Ao contrário de outros elementos da geodiversidade, a conservação do patrimônio paleontológico ex-situ pode manter o seu valor científico, educativo e turístico. As coleções museológicas, desde que bem geridas e colocadas à disposição de todos, são usadas para pesquisas científicas por paleontólogos (valor científico), são visitadas por estudantes de diversos graus de ensino (valor educativo) e são admiradas pelo público em geral (valor turístico).

O patrimônio geológico está sujeito a diversos tipos de ameaças (Gray 2004; Brilha 2005), a grande parte delas de origem antrópica. Algumas destas ameaças são particularmente fortes sobre os bens paleontológicos, em particular. O elevado valor econômico de alguns fósseis, em resultado de fatores como raridade, qualidade de preservação, valor estético, etc., dão origem a um comércio que, em grande parte dos países, é ilegal, colocando em risco muitas jazidas paleontológicas, em especial em países com níveis socioeconômicos mais débeis. Segundo Carvalho \& DaRosa (2008), a questão da preservação do patrimônio paleontológico brasileiro é bastante complexa. 0 contrabando nacional e internacional de fósseis, bem como as atividades de exploração mineral, são fatores que limitam a adoção de estratégias de conservação, em comunidades onde as jazidas fossilíferas representam uma fonte de rendimento para as populações.

O aumento da pesquisa científica, desde a década de 70 do século XX, destacou a alta diversidade e qualidade do registro paleontológico da bacia do Araripe, no nordeste brasileiro. Porém, este aumento de visibilidade contribuiu para um incremento do interesse generalizado deste registro, que associado a poucas medidas efetivas para a sua conservação, originou um maior risco de perda dos fósseis, em especial devido ao comércio ilegal (Kellner 2002; Viana \& Neumann 2002; Viana 2002; Martill 2011; Vilas-Boas 2012). Além disso, nesta região, a conservação dos elementos paleontológicos está em permanente conflito com a mineração, atividade de grande relevância econômica e social que suporta uma percentagem significativa da população.

A criação do Geopark Araripe, que pretende promover o desenvolvimento sustentável dos municípios constituintes do seu território e a melhoria das condições de vida dos seus habitantes, constitui uma estratégia que pode contribuir para a conservação do patrimônio paleontológico local sujeito a uma depredação já documentada. Este trabalho pretende elencar as razões que explicam as ameaças ao patrimônio paleontológico no Araripe e propor programas, projetos e ações de cunho educativo, que podem ser implementados pelo Geopark Araripe, para apoiar a conservação deste notável patrimônio paleontológico brasileiro e mundial.

\section{ENQUADRAMENTO LEGAL PARA A PROTEÇÃO DO PATRIMÔNIO PALEONTOLÓGICO BRASILEIRO}

De acordo com a legislação brasileira, existe uma base legal para a proteção do patrimônio paleontológico. Atualmente, no ordenamento jurídico brasileiro, embora alvo de várias interpretações, os fósseis são definidos como bens integrantes do patrimônio cultural (artigo 216ㅇ da Constituição Federal CF), com natureza de bem de domínio público (nos termos do artigo 20ㅇ da CF). Os fósseis são também regidos pelo Decreto-lei no 4.146/42 onde se refere que "os depósitos fossilíferos são propriedade da Nação, e, como tais, a extração de espécimes fósseis depende da autorização prévia do Departamento Nacional de Produção Mineral, do Ministério da Agricultura" (atualmente o Departamento Nacional de Produção Mineral - DNPM, vincula-se ao Ministério de Minas e Energia). Porém, a conservação do patrimônio paleontológico no Brasil ainda está longe de atingir os resultados preconizados pela respectiva legislação. 0 conjunto das leis brasileiras apresenta subjetividade no que respeita à sua aplicação, de forma a possibilitar a preservação de jazidas fossilíferas, enquanto patrimônio cultural da sociedade brasileira, como também parece ser insuficiente para assegurar a proteção destes bens, enquanto propriedade da União (Abaide 2009).

Em função das peculiaridades do material fóssil, previsivelmente existe uma contraposição na fixação de competências para a gestão do património paleontológico. Como o património paleontológico é considerado património cultural por determinação legal (artigo 216. da CF), o IPHAN (Instituto do Património Histórico e Artístico Nacional) deve zelar por medidas de proteção a esse património (Dresh 2006). Mas por outro lado, devido ao Decreto-lei 4.146/42, o DNPM tem a responsabilidade de fiscalizar e controlar o exercício das atividades relacionadas ao património fossilífero (colheita, transporte, entre outras) de modo a assegurar a sua proteção. Para além da questão legal, parece haver alguma dificuldade de atuação do DNPM no que respeita à proteção e conservação do patrimônio paleontológico brasileiro, em especial pelo fato de existirem extensas e numerosas áreas de mineração sob a fiscalização de um reduzido número de técnicos.

\section{GEOPARK ARARIPE}

O Geopark Araripe foi criado a partir da iniciativa da Universidade Regional do Cariri (URCA) em parceria com o Governo do Estado do Ceará. Foi aceito, em 2006, na Rede Global de Geoparques, sendo até hoje o único geoparque da América do Sul a integrar esta estrutura internacional, reconhecida pela UNESCO.

O geoparque localiza-se no sul do estado do Ceará, na região nordeste do Brasil (Figura 1) e integra os municípios de Barbalha, Crato, Juazeiro do Norte, Missão 
Velha, Nova Olinda e Santana do Cariri, totalizando uma área de $3796 \mathrm{~km}^{2}$. A gestão do geoparque é atribuição da URCA e possui um grupo amplo de apoio institucional: uma coordenação executiva; um conselho de gestão formado por representantes de instituições do terceiro setor, poder público municipal, estadual e federal, e iniciativa privada; um comitê científico formado por investigadores da URCA e outras instituições de pesquisa do território; e uma equipe técnica com profissionais de diferentes formações acadêmicas. Além disso, a estrutura do Geopark Araripe também compreende o Museu de Paleontologia da URCA, em Santana do Cariri.

A estratégia adotada para o Geopark Araripe é a promoção do desenvolvimento territorial sustentável da região, tendo como mote principal o fortalecimento de atividades científicas, culturais, turísticas e econômicas, com ênfase na história evolutiva da Terra e da Vida.

O campo de atuação do Geopark Araripe abrange atividades no âmbito do patrimônio geológico, biológico, arqueológico e cultural, como também da educação ambiental. O Museu de Paleontologia da URCA promove a aproximação entre o conhecimento paleontológico e as escolas públicas e particulares da região do Cariri, possibilitando a visitação de alunos e professores. $\mathrm{Na}$ pesquisa científica, destaca-se a realização de escavações paleontológicas, dentro do geossítio Parque dos Pterossauros, e também o projeto "Jovens Paleontólogos" desenvolvido pelo Geopark Araripe em parceria com o museu e escritório do DNPM no Crato. Neste projeto, jovens do ensino médio do município de Santana do Cariri, são capacitados nas temáticas de geologia e paleontologia, visando o levantamento de dados e a coleta de materiais paleontológicos nas explorações de calcário da região.

O Centro de Interpretação e Educação Ambiental do Geopark Araripe, localizado no município do Crato, constitui outro importante ponto de apoio para a recepção de escolas e visitantes. Possui um espaço de exposição e interpretação dos principais elementos naturais e culturais do geoparque, onde também têm lugar oficinas lúdicas, no âmbito da educação ambiental, com o objetivo envolver a comunidade, em especial as escolas. Todas as atividades estão relacionadas com os propósitos do geoparque, nomeadamente oficinas de réplicas de fósseis, teatro de bonecos, reutilização de materiais recicláveis, entre outras.

Tem-se verificado uma expressiva consolidação da proposta de geoparque no território desde 2009, em especial ao nível da educação ambiental, da geoconservação, da comunicação e promoção do geoturismo e do aumento da efetivação de parcerias com os diversos atores do território. Contudo, é notório o forte sistema burocrático adotado, que dificulta a tomada de decisões em tempo útil. Muitas das atividades desenvolvidas pelo Geopark Araripe apresentam um caráter pontual, sem continuidade temporal, o que diminui a sua eficácia quanto aos resultados esperados e possíveis de alcançar.

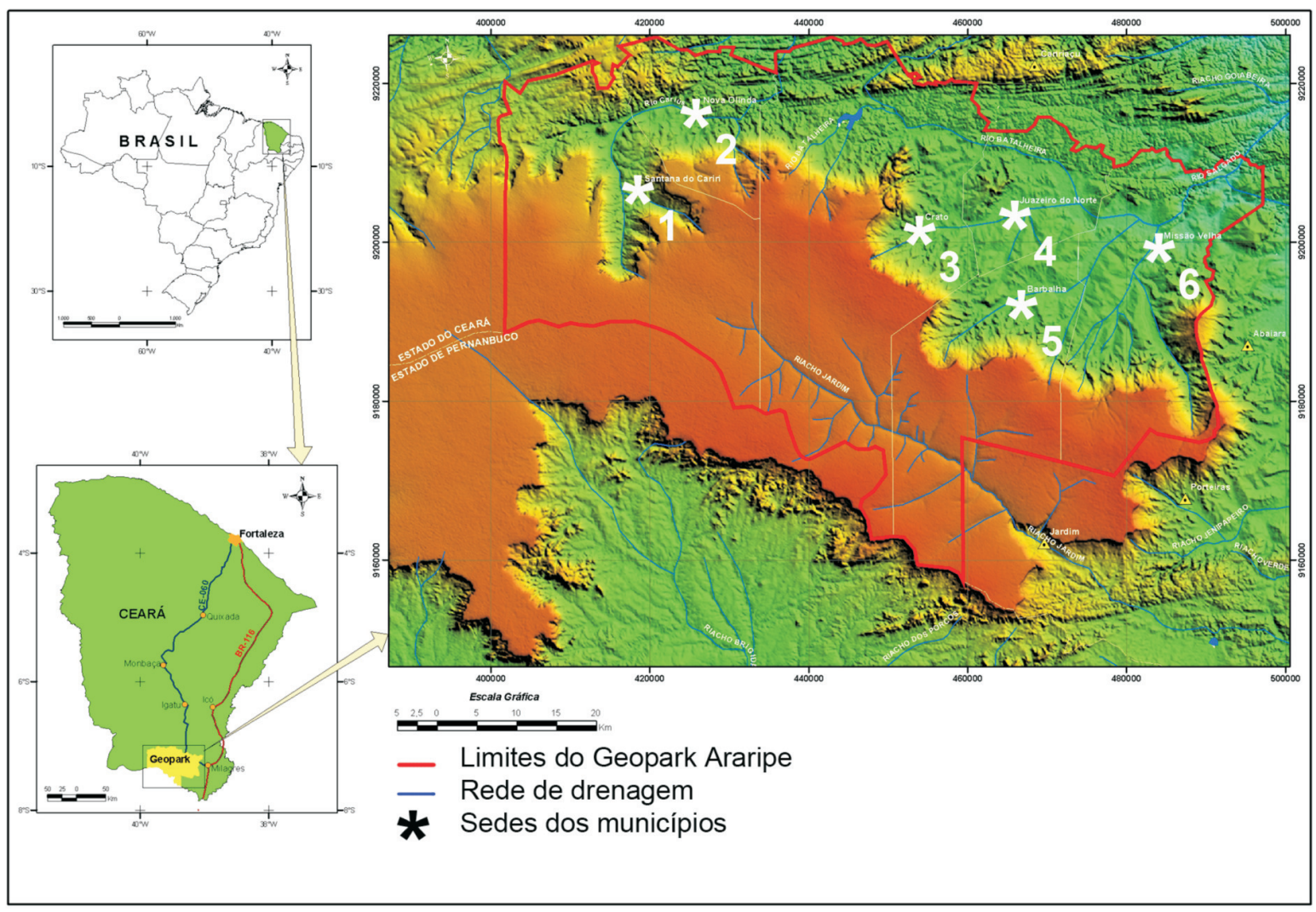

Figura 1 - Mapa de localização do geoparque no Brasil e no estado do Ceará. Sede dos municípios do Geopark Araripe: *1-Santana do Cariri; *2 - Nova Olinda; *3 - Crato; *4 - Juazeiro do Norte; *5-Barbalha; *6 - Missão Velha (adaptado de Geopark Araripe 2010). 
A evidência morfoestrutural mais significativa na área do Geopark Araripe é representada pela Chapada do Araripe, um planalto que apresenta altitudes médias que variam entre 700 e 1000 metros (Geopark Araripe 2010).

Quanto ao enquadramento geológico geral, o geoparque insere-se na área da bacia sedimentar do Araripe, que se estende pelos estados do Ceará, Pernambuco e Piauí. É a mais extensa das bacias interiores do nordeste do Brasil, sendo que a sua ocorrência engloba a Chapada do Araripe e o Vale do Cariri (Assine 1992). A bacia sedimentar do Araripe apresenta uma complexa história geológica, constituída por sequências estratigráficas, limitadas por discordâncias regionais, que representam o registo fragmentário da formação de bacias em ambientes tectônicos distintos (Assine 2007). A bacia está estreitamente ligada aos períodos Jurássico e Cretáceo, quando os continentes da América do Sul e da África eram parte do antigo continente Gondwana, que lentamente se separou com a abertura do oceano Atlântico Sul (Herzog et al. 2008). Entre as várias formações da bacia do Araripe, a Formação Santana é estratigraficamente a mais complexa e também a mais estudada, não só pelas extensas jazidas de gipsita, mas principalmente por constituir o principal depósito fossilífero brasileiro (Assine 1992). Na verdade, o
Geopark Araripe insere-se numa região conhecida internacionalmente pelo importante registro geológico do Período Cretáceo, com particular destaque para o seu conteúdo paleontológico, que apresenta um excepcional estado de preservação e uma enorme diversidade biológica dos fósseis.

\section{O PATRIMÔNIO PALEONTOLÓGICO DO GEOPARK ARARIPE}

O reconhecimento nacional e internacional do Geopark Araripe é, em grande parte, fruto da sua riqueza paleontológica associada à bacia sedimentar do Araripe que contém, à escala mundial, uma das mais importantes associações fossilíferas do Cretáceo Inferior. A notória diversidade de fósseis da bacia sugere a existência de um ambiente pretérito favorável à vida, associado a condições especiais de pós-morte que favoreceram a fossilização. A distinção de Konservat-Lagerstätten é aplicada à Formação Santana pois esta apresenta fósseis com um grau de preservação extraordinário.

Segundo Assine (2007), a Formação Santana é constituída pelas Camadas Ipubi (gipsita) e pelos Membros Crato e Romualdo, dois dos principais depósitos fossilíferos do Brasil e do mundo desta idade (Figura 2).

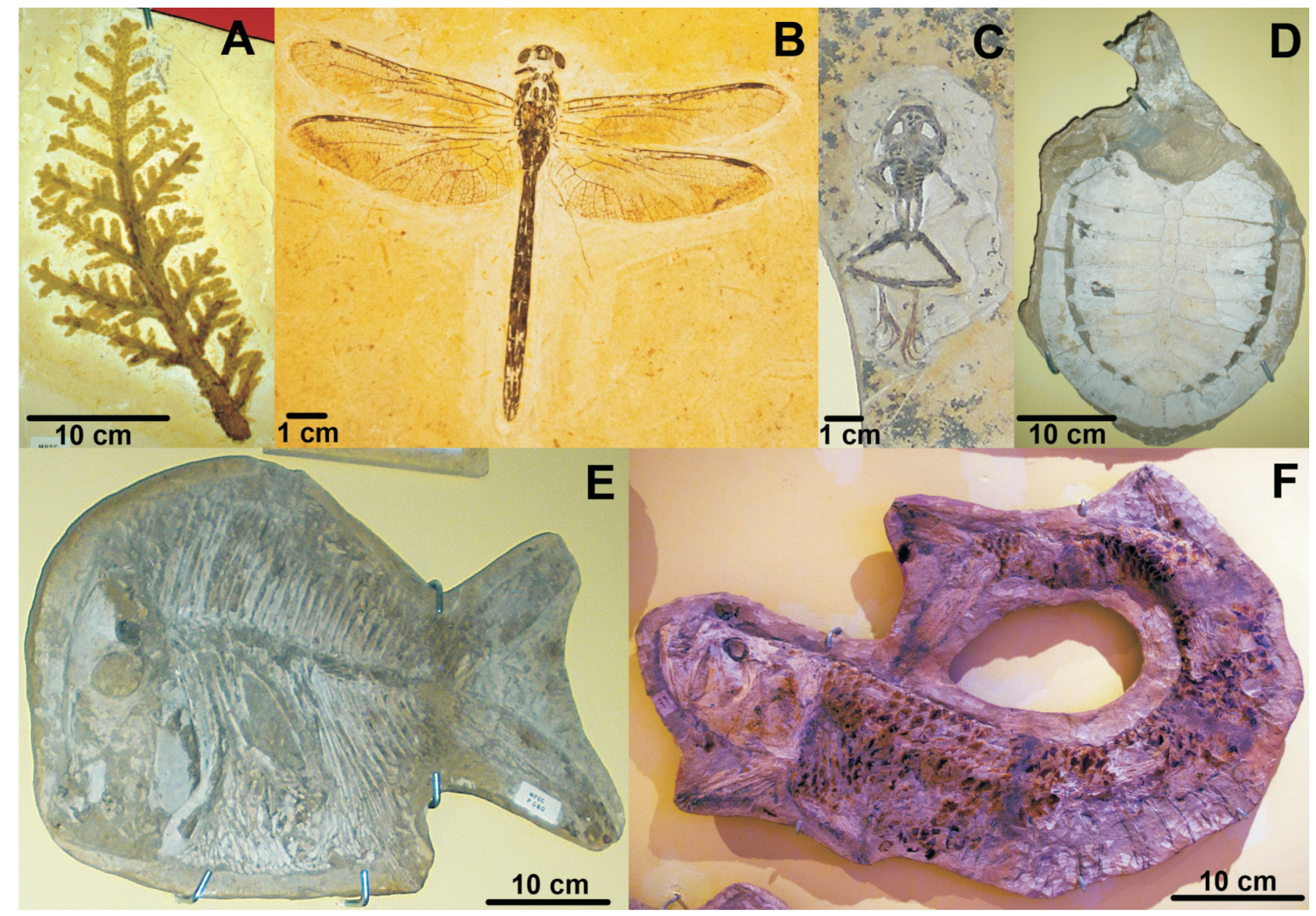

Figura 2 - Alguns exemplares da riqueza fossilífera da Formação Santana. Membro Crato: A, Brachyphyllum obesum Heer, 1881; B, Cordulagomphus fenestratus Carle \& Wighton, 1990; C, Arariphrynus placidoi Leal \& Brito, 2006. Membro Romualdo: D, Araripemys barretoi Price, 1973; E, Neoproscinetes penalvai Figueiredo \& Silva Santos, 1987; F, Cladocyclus gardnery Agassiz, 1841 (a nomenclatura dos fósseis foi obtida em Moura et al. 2006 e em Saraiva et al. 2010). 
O Membro Crato representa a sequência inferior da Formação Santana e possui origem lacustrina. Apesar da maioria dos estudos paleontológicos deste membro ter início na década de 1980 , em pouco mais de 20 anos foram descobertas e descritas mais de 200 novas espécies a partir das rochas do Membro Crato (Martill \& Bechly 2007). Este registro fossilífero destaca-se pela diversidade, abundância e qualidade de preservação de fósseis, nomeadamente fósseis de algas, vegetais, artrópodes, moluscos, peixes, anfíbios, pterossauros e penas de aves (Carvalho \& Santos 2005). Esta diversidade de grupos zoológicos e botânicos justifica que a comunidade científica direcione esforços para o reconhecimento geológico e caracterização da paleobiota, colocando os afloramentos desta formação entre os mais importantes sítios paleontológicos mundiais (Lima 1979; Barreto et al. 2000; Barreto et al. 2012). Destaca-se ainda a grande abundância e diversidade de espécies representantes da classe Insecta, que corresponde a cerca de $80 \%$ das espécies descritas para este membro (Moura et al. 2006).

A preservação dos exemplares fósseis do Membro Romualdo, que representa a sequência estuarina, é, na maioria dos casos, excepcional o que tornou este material paleontológico conhecido em nível nacional e internacional (Kellner 2002). Este membro apresenta uma biota diversificada, com exemplares fósseis de vegetais, artrópodes, moluscos, equinoides, peixes, dinossauros terópodes, além de uma grande variedade de pterossauros (Carvalho \& Santos 2005). A ictiofauna constitui o grupo de organismos mais abundantes, sendo composta por mais de 19 gêneros pertencentes a várias famílias (Wenz et al. 1993; Maisey 2000 apud Fara et al. 2005). Os fósseis são encontrados principalmente em nódulos e concreções calcárias, sendo comum a preservação tridimensional sem exibir sinais de compactação (Kellner 2002). É ainda frequente a ocorrência de espécimes totalmente articulados e fósseis de vertebrados e invertebrados com elevada qualidade de preservação dos tecidos moles (Martill
1988; Kellner 1996; Kellner \& Campos 1998; Smith 1999 apud Fara et al. 2005).

Na região do Geopark Araripe, este patrimônio paleontológico está acessível no Museu de Paleontologia da Universidade Regional do Cariri, no município de Santana do Cariri (que reúne uma coleção superior a 3 mil exemplares) e no Centro de Pesquisas Paleontológicas da Chapada do Araripe (CPCA) vinculado ao DNPM, no município do Crato (Carvalho \& Da-Rosa, 2008).

\section{AMEAÇAS AO PATRIMÔNIO PALEONTOLÓGICO DO GEOPARK ARARIPE}

São várias as ameaças que afetam a conservação do patrimônio paleontológico do Geopark Araripe e, de modo geral, de toda a região da bacia do Araripe. O comércio de fósseis ao longo das últimas décadas tem representado uma verdadeira ameaça ao patrimônio paleontológico da região do Araripe e do país, apesar de ser ilegal no Brasil. As inúmeras descobertas de novos exemplares de grande qualidade fez com que estes fósseis começassem a ser mais valorizados por cientistas, museus, colecionadores e paleontólogos amadores, aumentando a demanda por novas amostras. Como em qualquer relação comercial, o comércio de fósseis está baseado numa relação entre a "oferta" e a "procura" (Tabela 1). Por um lado, a "oferta" é sustentada por uma população inserida numa região com uma situação socioeconômica desfavorecida, que não reconhece nem valoriza os fósseis enquanto patrimônio de todos. Por outro lado, a relevância científica e estética dos fósseis, que thes confere um elevado valor econômico, contribui para a existência de uma "procura" diversificada. O excelente grau de preservação, a sua beleza, o fato de serem exemplares representativos do seu tempo geológico e até mesmo todo o imaginário criado à sua volta, fazem destes fósseis um objeto de contemplação pelo cidadão comum e um precioso bem científico, desejado pela comunidade científica paleontológica. 
Vilas Boas et al./Boletim Paranaense de Geociências 70 (2013) 156-165

\begin{tabular}{|l|l|}
\hline \multicolumn{2}{|c|}{ Comércio ilegal de fósseis no Araripe } \\
\hline \multicolumn{1}{|c|}{ OFERTA } & \multicolumn{1}{c|}{ PROCURA } \\
\hline $\begin{array}{l}\text { Fatores } \\
\text { - Vasta ocorrência de fósseis, em parte resultado da } \\
\text { atividade extrativa; }\end{array}$ & - Relevância científica dos fósseis; \\
$\begin{array}{l}\text { - Baixo nível salarial dos trabalhadores das pedreiras } \\
\text { que encaram a venda de fósseis como complemento } \\
\text { de renda; }\end{array}$ & - Relevância estética dos fósseis; \\
- Deficiente fiscalização e controle por parte do DNPM \\
$\begin{array}{l}\text { e das forças policiais; } \\
\text { - Reduzida conscientização social sobre o real } \\
\text { significado e valor patrimonial dos fósseis. }\end{array}$ \\
$\begin{array}{l}\text { Atores } \\
\text { - Trabalhadores das pedreiras; }\end{array}$ \\
$\begin{array}{l}\text { - Intermediários. } \\
\text { Coletores amadores; }\end{array}$ & - Elevado valor econômico aos fósseis. \\
\hline
\end{tabular}

Tabela 1-Fatores e atores que dominam a relação entre a "oferta" e a "procura" e que enquadra o comércio ilegal de fósseis no Araripe.

A vasta ocorrência de fósseis na região da bacia do Araripe é, em parte, resultado da atividade de exploração mineral, onde os trabalhadores apresentam baixo nível salarial e encaram a venda de fósseis como um complemento de renda. Infelizmente, são poucos os proprietários das pedreiras que estabelecem procedimentos rigorosos para os trabalhadores não recolherem os fósseis para posterior venda. Para a extração da gipsita (Camadas Ipubi da Formação Santana), normalmente as pedreiras removem toda a camada de rochas que está sobrejacente. Esta é a camada correspondente ao Membro Romualdo, uma das mais fossilíferas da Formação Santana. Como resultado desta atividade, o nível de concreções fossilíferas exposto é, comumente, depositado nas enormes acumulações de "rejeitos". Apesar da exploração de gipsita ser essencialmente na parte sudoeste da Chapada do Araripe (Pernambuco), a maior parte dos registros da recolha ilegal de fósseis centra-se no Ceará, sendo apenas alguma em Pernambuco (Vidal \& Castro 2009). No Piauí, como não existe exploração de gipsita, as concreções calcárias são encontradas em menor quantidade. Para além desta ocorrência de concreções fossilíferas, típicas do Membro Romualdo, na exploração do calcário laminado ocorre um número surpreendentemente elevado de fósseis de alta qualidade do Membro Crato (Martill \& Bechly 2007). No lado leste da Chapada do Araripe, coincidente com a área do Geopark Araripe, existe a indústria da "Pedra Cariri", para produção de rochas ornamentais (pedras de pavimentação e revestimento) e também de cimento. Devido à informalidade e alta rotatividade dos produtores é difícil ter um controle do material fossilífero que tem origem nas áreas de mineração, para fins comerciais. Apesar de ser um ato ilegal, sabe-se que parte da venda dos fósseis da bacia do Araripe está associada às explorações de calcário laminado. Os destinatários desta venda são vários, desde revendedores conhecidos na região, colecionadores particulares e até pesquisadores ligados às universidades.

Além destes fatores, a falta de fiscalização eficaz e a existência de legislação com caráter subjetivo no que respeita ao patrimônio paleontológico, têm contribuído para o comércio ilegal de fósseis. As leis, apesar de terem sido criadas para proteger os fósseis muito raros e cientificamente importantes, determinam de forma muito confusa quem tem competência para avaliar e preservar o patrimônio paleontológico. A única regulação sobre fósseis não está enquadrada no Código de Mineração, nem na lei de patrimônio cultural, mas sim numa lei especial (Decreto Lei 4.146/42) que não estabelece nenhum regime para além de definir a competência do órgão responsável pelo setor mineiro nacional para fiscalizar e autorizar a extração de fósseis com fins científicos. Segundo o Decreto-Lei 4.146/42, os fósseis estão sob fiscalização do DNPM, uma vez que estes integram os bens e riquezas do solo que compõem 
o domínio da União mas, ao mesmo tempo, são considerados como bens integrantes do patrimônio cultural, onde a lei confere a fiscalização ao órgão da cultura (IPHAN).

\section{ESTRATÉGIAS PARA A CONSERVAÇÃO DO PATRIMÔNIO PALEONTOLÓGICO DO GEOPARK ARARIPE}

A solução para reduzir, ou mesmo eliminar, as ameaças ao patrimônio paleontológico do Geopark Araripe não é simples uma vez que estas são sustentadas por fatores diversos. Alguns desses fatores estão relacionados com a raridade e qualidade de preservação e outros são de tal amplitude que não permitem a implementação de medidas que dependem apenas do Geopark Araripe, mas sim de várias instituições em nível federal e estadual. No entanto, o geoparque pode fazer um importante trabalho com as comunidades locais, especialmente no que se refere à educação.

A promoção da educação é essencial em qualquer programa de desenvolvimento sustentável, particularmente numa estratégia de geoconservação em geoparques. Com efeito, práticas cotidianas de conservação do patrimônio paleontológico, protagonizadas pelos cidadãos, só se efetivam se estes compreenderem o caráter excepcional da fossilização e a relevância do registro fóssil para o conhecimento da história da vida na Terra e para a antevisão do futuro do planeta (Henriques 2007). Assim, é proposta uma estratégia educativa com várias ações de âmbito formal e informal que visam consolidar a prática da conservação do patrimônio paleontológico no Geopark Araripe. Esta estratégia educativa foi planejada de forma a atingir o máximo da população do geoparque e tanto é aplicável neste território, como noutras áreas fossilíferas do Brasil e até mesmo de outros países, com eventuais adaptações a outras realidades.

\subsection{AÇÕES EDUCATIVAS FORMAIS}

As ações educativas de caráter formal têm como finalidade difundir o conhecimento sobre o patrimônio paleontológico do Geopark Araripe e alertar a comunidade escolar sobre a importância da prática da geoconservação, assim como disponibilizar novas ferramentas educativas aos professores. É proposto um curso de formação para professores que lecionam Ciências e Geografia no nível de ensino médio, com a duração de 2 dias. O curso contemplaria uma parte teórica, onde seriam discutidos conceitos de geoconservação e apresentado o patrimônio paleontológico do Geopark Araripe. Na parte prática são propostas aulas de campo, as quais proporcionariam aos professores uma forma mais estimulante de abordagem sobre o geoparque e o seu patrimônio paleontológico. No caso dos professores não possuírem uma formação científica mínima sobre geociências, este curso deve ser antecedido de um outro onde seriam ministrados conhecimentos básicos de paleontologia, geologia sedimentar e tempo geológico.

\subsection{AÇÕES EDUCATIVASINFORMAIS}

A educação informal do público em geral é um aspecto muito relevante na perspectiva da sustentabilidade de um geoparque. $O$ entendimento dos conceitos da conservação do patrimônio natural e cultural e o respeito pela identidade regional são essenciais para um padrão de desenvolvimento diferenciado, como é entendido pelo conceito de geoparque (Baci et al. 2009). Neste sentido, são propostas várias ações educativas de caráter informal, dirigidas ao público em geral, nomeadamente à população local, trabalhadores das pedreiras e turistas. Estas ações foram planejadas tendo em conta as características socioeconômicas da população local, mas também a promoção de um turismo sustentável.

\subsubsection{Exposição itinerante de fósseis do Araripe}

Com esta ação pretende-se divulgar o patrimônio paleontológico do Geopark Araripe, em que o seu público-alvo é constituído pelos estudantes e o público em geral.

Consiste na organização de uma exposição itinerante com fósseis da bacia do Araripe e que deverá percorrer os seis municípios que integram o Geopark Araripe. Esta exposição deverá ser exibida em locais que possam atrair o maior número possível de visitantes, assim como em todas as escolas do geoparque.

\subsubsection{Concurso: O fóssil do ano}

O concurso é dirigido à população local, e em particular aos trabalhadores das pedreiras. 0 principal objetivo desta iniciativa é distinguir cidadãos residentes no território do Geopark Araripe que doam fósseis por eles resgatados. Também tem como finalidade contribuir para a salvaguarda de mais e melhores fósseis e sensibilizar a sociedade para a importância do patrimônio paleontológico da região.

Este concurso deverá ser promovido pelo Geopark Araripe, com o apoio do Museu de Paleontologia da URCA e do DNPM, escritório regional do Crato. Todos os anos, um júri avalia as ofertas que forem feitas e atribui um certificado a quem resgatar e entregar o exemplar fóssil com maior valor científico/educativo. Este fóssil deverá integrar a coleção do Museu de Paleontologia, com reconhecimento público expresso ao seu doador.

\subsubsection{Fóssil Quiz}

Com esta iniciativa pretendemos divulgar 
informações sobre o patrimônio paleontológico do Araripe, para o público em geral. Esta ação consiste em colocar questões diversas, na página do geoparque na internete, sobre o patrimônio paleontológico local e que podem ser respondidas pelo público. Todos os meses será elaborada uma nova questão e será selecionada a pessoa que der a resposta correta no mês anterior (terá de haver um sorteio, no caso de haver várias respostas corretas). Ao vencedor seria atribuído um prêmio simbólico alusivo ao Geopark Araripe.

\subsubsection{Ser paleontólogo por dois dias}

Esta é uma ação para candidatos a paleontólogo amador, que tem como público-alvo os turistas e o público em geral. Pretende-se proporcionar a experiência de ser paleontólogo promovendo, em simultâneo, o contato do geoparque com as pedreiras locais. O programa desta atividade seria distribuído por dois dias, mas poderia ser dada oportunidade de participar apenas no primeiro dia. Depois de uma breve apresentação sobre o patrimônio paleontológico do Araripe, o participante seria convidado a recolher fósseis que ocorrem nas lajes calcárias extraídas nas explorações de "Pedra Cariri". Também seria ministrado um rápido treinamento sobre como proceder numa primeira seleção e tratamento dos exemplares recolhidos, recorrendo a um kit de paleontólogo fornecido aos participantes (martelo de bico chato, pincel, lupa, talhadeira e papel para embrulhar as amostras). Durante o segundo dia seria realizado o tratamento dos exemplares selecionados anteriormente. Dependendo do estado do material, seriam facultadas técnicas de preparação mecânica e limpeza das amostras. Numa fase posterior, estas amostras poderiam ser colocadas na exposição do próprio museu, como também poderiam ser aproveitadas para outras exposições, por exemplo naquelas propostas na ação "Exposição itinerante dos fósseis do Araripe".

Durante toda a atividade os participantes devem ser acompanhados por um paleontólogo, ou responsável do geoparque com formação adequada. Destaca-se também que, durante o recolhimento dos fósseis nas mineradoras, os participantes estarão sempre sob a orientação do DNPM e de um trabalhador da empresa destacado para o efeito.

\subsubsection{Escavação paleontológica para estudantes}

Os estudantes do ensino médio são público-alvo desta ação, que pretende que estes vivenciem as atividades de coleta e preparação de fósseis, promovendo o envolvimento das pedreiras locais no geoparque.

Os estudantes (máximo 10) do ensino médio de diferentes escolas da região seriam convidados a participar numa semana de coleta de fósseis. Durante o período de férias escolares, os jovens efetuariam trabalhos com fósseis nas lajes calcárias extraídas nas pedreiras da região. Fariam também uma primeira seleção e tratamento dos exemplares recolhidos, sob a orientação de um professor ou responsável pela atividade. Alguns dos fósseis encontrados pelos estudantes seriam doados às respectivas escolas, com a ficha técnica completa e identificação do aluno que o resgatou. Esta atividade deve decorrer sempre sob a supervisão do DNPM.

\subsubsection{Empresa amiga do fóssil}

Esta ação é dirigida especialmente às empresas mineradoras e tem com objetivo principal criar uma parceria entre o geoparque e as empresas, de forma a promover a conservação dos fósseis e destacar o importante papel das mineradoras no resgate dos mesmos. Propõe-se a atribuição, por parte do geoparque, de um selo "empresa amiga do fóssil" para as mineradoras que colaborarem com as atividades desenvolvidas pelo geoparque e que doarem os fósseis que vão sendo encontrados durante a atividade de mineração. Esta ação deverá ter o apoio do Museu de Paleontologia da URCA e do DNPM.

\section{CONCLUSÕES}

No Geopark Araripe, dentre os vários tipos de patrimônio geológico, o paleontológico é dos que mais se encontra sujeito a pressões antrópicas que podem contribuir para a sua perda irreparável. Toda a região da bacia do Araripe enfrenta o grande problema do comércio ilegal de fósseis. Este é resultado de um conjunto de fatores interligados, que materializam várias ameaças à integridade do patrimônio paleontológico. Atualmente, apesar do aumento de condicionantes legais e das políticas de fiscalização, esta prática persiste de uma forma mais comedida, mas não menos alarmante. Existe uma "procura" pela qualidade e não pela quantidade, isto é, a procura pelos fósseis é menos intensa mas, no entanto, seletiva na medida em que os fósseis mais raros e com maior valor científico, continuam a sair da região e até mesmo do território brasileiro.

Mediante a magnitude dos vários fatores que afetam diretamente a conservação do patrimônio paleontológico, entende-se que o campo de atuação do Geopark Araripe deverá estar próximo da população. É proposto que o geoparque tenha como alvo os "atores" intervenientes na perda deste patrimônio paleontológico de relevância mundial, ou seja, as pessoas que de forma, direta ou indireta, podem influenciar o destino dos fósseis da região.

O Geopark Araripe está inserido numa região economicamente desfavorecida, onde a população enfrenta vários problemas de ordem social e educativa. 
Como consequência, esta população denota um baixo reconhecimento da importância do patrimônio paleontológico local. Este fato está na base das razões que levam à existência de uma "oferta" de fósseis que alimenta o comércio ilegal, obviamente complementado pela sua vasta ocorrência na região e uma deficiente fiscalização e controle por parte do poder público. Por outro lado, a "procura" pelos fósseis é sustentada por pessoas que os valorizam pela sua importância científica e até mesmo pela sua beleza, e que também estão disponíveis para os comprar, características que aumentam ainda mais a valoração econômica deste patrimônio.

Apesar de ser necessário encontrar uma rápida e definitiva solução para a conservação do patrimônio paleontológico do Araripe, destaca-se que a estratégia educativa proposta, para ser implementada pelos gestores do Geopark Araripe, dificilmente irá produzir resultados duradouros a curto prazo. No entanto, tendo em conta a dimensão e variedade dos fatores que propiciam a depredação do patrimônio paleontológico, as ações educativas concebidas são uma contribuição no combate ao comércio dos fósseis.

Em complemento a esta estratégia educativa, o incremento da fiscalização e a consequente aplicação das leis vigentes no país, ambos fora das competências do Geopark Araripe, poderiam dar um importante sinal aos compradores que, de alguma forma, incentivam a coleta de fósseis por parte de uma população ainda pouco esclarecida. É sobre os compradores que as medidas fiscalizadoras e repressivas devem ser mais incisivas, uma vez que a redução de seu número certamente conduzirá a uma diminuição da coleta de fósseis desincentivando, deste modo, o comércio de patrimônio paleontológico.

Terminar com o comércio ilegal de fósseis pode parecer uma pretensão ingênua. Desde que haja um fóssil com valor econômico e um potencial comprador, existem condições para que este bem seja negociado. No entanto, os geoparques, enquanto instrumentos de desenvolvimento territorial, possuem a obrigação de criar estratégias que promovam a conscientização da sociedade e a necessária mudança de mentalidades que, inevitavelmente, vão contribuir para o tão almejado desenvolvimento sustentável.

\section{Referências}

ABAIDE J.P. 2009. Fósseis. Riqueza do Subsolo ou Bem Ambiental? 2a Ed., Curitiba: Juruá, 348p.

AASSINE M. L. 1992. Análise estratigráfica da Bacia do Araripe, nordeste do Brasil. Revista Brasileira de Geociências 22 (3): 289-300.

ASSINE M.L. 2007. Bacia do Araripe. Boletim. Geoci. Petrobras, Rio de Janeiro, 15 (2): 371-389.

BACCI D. de La C., PIRANHA J. M., BOGGIANI P.C. LAMA E.A. \& TEIXEIRA W. 2009. Geoparque: estratégia de geoconservação e projetos educacionais. Revista do Instituto de Geociências da USP. Publicação especial. São Paulo. V.5, 7-15.

BARRETO A.M.F., BERNARDES-DE-OLIVEIRA M.E.C., DILCHER D., MANDARIM-DE-LACERDA A.F. \& VIANA M.S.S. 2000. Fruto monocarpelar Eocretáceo do Membro Crato, Formação Santana, Bacia do Araripe, Nordeste do Brasil. Revista Geociências, Universidade Guarulhos, V (noespecial): 121-124.

BARRETO A.M.F., BRILHA J., SALES A.M.F. \& ALMEIDA J.A.C. 2012. Patrimônio Paleontológico e Geoconservação da Formação Santana (Cretáceo Inferior da Bacia do Araripe, Pernambuco e Piauí Nordeste do Brasil). In: Henriques M.H., Andrade A.I., Quinta-Ferreira M., Lopes F.C., Barata M.T., Pena dos Reis R., Machado A. (Coords). Para Aprender com a Terra. Memórias e Notícias de Geociências no Espaço Lusófono. Imprensa da Universidade de Coimbra, Cap. 33, 311-320p.

BESTERMAN T.P. 1988. The use and conservation of palaeontological sites. The paleontological association. London, Crowther P.R. \& Wimbledon W.A. Editors 199p.
BRILHA J. 2005. Património Geológico e Geoconservação: A Conservação da Natureza na sua Vertente Geológica. Viseu: Palimage Editores, 190p.

CARVALHO I.S. \& DA-ROSA À.A.S. 2008. Patrimônio Paleontológico do Brasil: relevância para o desenvolvimento sócio-econômico. Publ. do Dep. Ciên. Terra e do Mus. Mineral. Geol., Univ. Coimbra. Memórias e Notícias, no3 (Nova Série), 15-28.

CARVALHO M.S.S. \& SANTOS M.E.C.M. 2005. Histórico das Pesquisas Paleontológicas na Bacia do Araripe, Nordeste do Brasil. Anuário do Instituto de Geociências 28 (1), 15-34.

GEOPARK ARARIPE 2010. Relatório Técnico Financeiro 2006-2010, Crato: Ceará, 127p. (relatório interno).

DRESH R.F.V. 2006. Breves apontamentos sobre a proteção legal ao Patrimônio Paleontológico. Paleontologia em Destaque, Boletim Informativo da Sociedade Brasileira de Paleontologia. Ano 21, n. 56, 12-13p.

FARA E., SARAIVA A.A.F., CAMPOS D.A., MOREIRA J.K.R., SIEBRA D. C. \& KELLNER A.W.A. 2005. Controlled excavations in the Romualdo Member of the Santana Formation (Early Cretaceous, Araripe Basin, northeastern Brazil): stratigraphic, palaeoenvironmental and palaeoecological implications. Elsevier, Palaeogeography, Palaeoclimatology, Palaeoecology, 218: 145-160.

GRAY M. 2004. Geodiversity: valuing and conserving abiotic nature. England: John Wiley and Sons, 434p. 
HENRIQUES M.H.P. 2007. Paleontologia- uma ponte entre as geociências e a sociedade. In: Carvalho I.S.; Cassab R.C.T.; Schwanke C.; Carvalho M.A.; Fernandes A.C.S.; Rodrigues M.A.C.; Carvalho M.S.S.; Arai M. \& Oliveira M.E.Q. (eds.). Paleontologia: Cenários de Vida, vol. 2, Editora Interciência, Rio de Janeiro, 171$183 p$.

HERZOG A., SALES A. \& HILMER G. 2008. The UNESCO Araripe Geopark: a short history of evolution of life, rocks and continents. Fortaleza: Expressão Gráfica e Editora, 80p.

KELLNER A.W.A. 1996. Fossilised theropod soft tissue. Nature, 379:32.

KELLNER A.W.A. 2002. Membro Romualdo da Formação Santana, Chapada do Araripe, CE- Um dos mais importantes depósitos fossilíferos do Cretácico brasileiro. In: Schobbenhaus, C.; Campos, D.A.; Queiroz, E.T.; Winge, M.; Berbert-Bom, M., Sítios geológicos e paleontológicos do Brasil. Brasília, DNPN, 121-130.

KELLNER A.W.A \& CAMPOS D.A. 1998. Archosaur soft tissue from Cretaceous of the Araripe Basin northeastern Brazil. Bol.Mus.Nac., 42, 1-22.

LIMA M.R. 1979. Paleontologia da Formação Santana (Cretáceo do Nordeste do Brasil): Estágio Atual de Conhecimentos. Anais da Academia Brasileira de Ciências, 51(3): 545-556.

MAISEY J.G. 2000. Continental break up and the distribution of fishes of Western Gondwana during the Early Cretaceous.Cretac. Res. 21, 281-314.

MARTILL D.M. 1988. Preservation of fish in the Cretaceous Santana Formation of Brazil. Palaeontology, vol.31 Part 1, 1-18.

MARTILL D.M. 2011. Protect and die. Geoscientist, The Geological Society of London, vol. 21 No 10, 12-17.

MARTILL D.M. \& BECHLY G. 2007. Introduction to the Crato Formation. In MARTILL D.M., BECHLY G. \& LOVERIDGE R.F. (eds) The Crato fossil beds of Brazil, Window into an Ancient World. Cambridge University press, Part I, 675p.

MOURA G.J.B., BARRETO A.M.F. \& BÁEZ A.M. 2006. A biota da Formação Crato, Eocretáceo da Bacia do Araripe, Nordeste do Brasil. Olinda: livro Rápido, editora Elógica, 100p.

SARAIVA A.A.F., BARROS O.A., BANTIM R.A.M. \& LIMA F.J. 2010. Guia para trabalhos de Campo em Paleontologia na Bacia do Araripe. Crato-Ceará, 88p.

SMITH R.J. 1999. Possible fossil ostracod (Crustacea) eggs from the Cretaceous of Brazil. J. Micropalaeontol. 18, 81-87.

VIANA M.S.S. 2002. 164 Anos de pesquisas paleontológicas na Chapada do Araripe: Formação Santana (Cretáceo Inferior). I e II Simpósios Sobre a Bacia do Araripe e Bacias Interiores do Nordeste, Crato (CE), coleção Chapada do Araripe no1, 195-211.
VIANA M.S.S. \& NEUMANN V.H.L. 2002. O Membro Crato da Formação Santana, Chapada do Araripe, Ceará: riquíssimo registro da fauna e flora do Cretaceo. In: Schobbenhaus, C.; Campos, D.A.; Queiroz, E.T.; Winge, M.; Berbert-Born, M., Sítios Geológicos e Paleontológicos do Brasil (SIGEP). Brasília, DNPM, 113-120.

VIDAL F.W.H. \& CASTRO N.F. 2009. Arranjo produtivo local de base mineral dos calcários do Cariri-CE. Relatório Técnico Final de Atividades (2005-2009) elaborado para a FINEP/FUNCAP de acordo com o covénio no 2678/2004 firmado entre SECITECE/CETEM, Rio de Janeiro, 131p.

VILAS-BOAS M.P. 2012. Património paleontológico do Geopark Araripe (Ceará, Brasil): análise e propostas de conservação. Dissertação de Mestrado, Departamento das Ciências da Terra, Universidade do Minho. Braga. 196p.

WENZ S., BRITO P.M. \& MARTILL D.M. 1993. The fish fauna of the Santana Formation concretions. In: Martill, D.M. (Ed.), Fossils of the Santana and Crato Formations, Brazil. Palaeont. Ass. Field Guide to Fossils, vol. 5, 76-107p. 